level (LDSL). Moreover, the correlations of the WLQ-subscales with functional disability and physical health were lower or similar in HDSL participants compared to LDSL participants.

Conclusion This study provides the first evidence that measurement properties of the WLQ-16 may vary by depressive symptom level in workers who returned to work after musculoskeletal disorders. More research is needed to better understand how health-related work functioning measures perform in workers with depressive symptoms.

\section{DETERMINANTS OF HEALTH, WORK ABILITY AND SICKNESS ABSENCE: THE INFLUENCE OF LIFESTYLE, WORK-RELATED FACTORS, AND WORK ENGAGEMENT}

${ }^{1}$ A Rongen, ${ }^{1}$ Robroek, ${ }^{2}$ Schaufeli, ${ }^{1}$ Burdorf. 'Erasmus MC, Rotterdam, Nederland; ${ }^{2}$ Universiteit Utrecht, Utrecht, Nederland

\subsection{6/oemed-2013-101717.34}

Objectives To identify the role of lifestyle factors, work-related factors, and work engagement on health, work ability, and sickness absence.

Methods Employees from two companies were invited to participate in a longitudinal study with questionnaires at baseline and six-month follow-up ( $\mathrm{n}=612$, response: $40 \%$ ). Lifestyle-related factors (physical activity, fruit and vegetable intake, body mass index), work-related factors (work demands, decision authority, skill discretion, physical job demands), and work engagement were assessed at baseline. At six-month follow-up, health, work ability, and sickness absence were assessed. Logistic regression analyses were performed to identify determinants of ill health, low work ability, and sickness absence. Additionally, additive interaction analyses were performed.

Results A low work engagement at baseline was associated with ill health (OR: 2.02, 95\% CI: 1.04-3.92) less than good work ability (OR: 3.51, 95\% CI: 2.01-6.12), and sickness absence (short: OR: 1.51, 95\% CI: 1.02-2.23, long: OR: 1.79, 95\% CI: 0.99-3.24) at follow-up. A lack of vigorous physical activity (ORs 2.46-2.96) and obesity (ORs: 2.34-3.02) at baseline were associated with ill health, low work ability, and long-term sickness absence at follow-up. Frequently working in awkward postures (ORs: 4.85-5.25) was related with a low work ability and long-term sickness absence. Unhealthy lifestyle and unfavourable physical work-related factors were associated with a low work engagement at baseline. The interaction effects of lifestyle or work-related factors and work engagement on work ability were stronger than the sum of the single effects.

Conclusion This study indicates that a low work engagement predicts ill health, a reduced work ability, and sickness absence. Furthermore, employees with an unhealthy lifestyle or unfavourable working conditions a low work engagement have a higher risk on a low work ability than their engaged colleagues. Hence, programs in occupational health should pay attention to both getting employees positively engaged in work and healthy in order to promote a productive work force.

\section{WORKING CONDITIONS AND HEALTH IN CENTRAL AMERICA}

${ }^{1}$ M L R López-Ruiz, 'Benavides, 'Wesseling, ${ }^{3}$ Delclos, ${ }^{4}$ Pinilla, ${ }^{1}$ Rodrigo. 'Center for Research in Occupational Health, Barcelona, Spain; ${ }^{2}$ Programa Salud, Trabajo y Ambiente en América Central, Universidad Nacional, San José, Costa Rica; ${ }^{3}$ School of
Public Health, University of Texas, Houston, United States of America; ${ }^{4}$ INSHT, Ministerio de empleo y Seguridad Social, Madrid, Spain

\subsection{6/oemed-2013-101717.35}

Objective To describe the initial results of the first Central American Survey of Working Conditions and Health, completed in 2011.

Methods A cross-sectional survey of a representative national sample of 12,024 workers (2004 per country) was performed in Costa Rica, El Salvador, Guatemala, Honduras, Nicaragua and Panama, by completing an interviewer-administered questionnaire in the homes of the participants. Questionnaire items addressed worker demographics, employment conditions, occupational risk factors and self-perceived health.

Results Among the most salient results, women worked mainly in the tertiary sector $(78 \%)$, while men were distributed between the tertiary (44\%) and primary sectors (37\%). Over $70 \%$ of both women and men were not insured by their country's social security system. Among salaried workers, $24 \%$ of women and $20 \%$ of men had a written contract, approximately $13 \%$ of both had an oral contract and 3\% had no contract. About $67 \%$ of workers reported having very good or good health status, but at the same time $40 \%$ of women and $35 \%$ of men self-reported poor mental health. Around 3\% of women and 5\% of men had sustained an occupational injury in the previous 12 months.

Conclusions In Central America there is a dearth of information on working conditions and health; the available information is generally considered unreliable, of poor quality and scant distribution, especially for the informal sector. The establishment of reliable information systems is a priority for several global health and development programs. Although more detailed analyses are underway, this survey already represents significant progress towards the development of a simple, representative and reproducible regional information system in occupational health and safety that could better inform national and regional planning and assessment, and the creation of public policies directed at preventing occupational risks and promoting the health of both formal and informal workers.

\section{OCCUPATIONAL HEALTH SERVICES FOR SMALL-SCALE INDUSTRY WORKERS IN A DISTRICT OF SRI LANKA}

${ }^{1} \mathrm{~S}$ A I K Suraweera, ${ }^{2}$ Wijesinghe, ${ }^{2}$ Senanayake. ${ }^{1}$ Environmental and Occupational Health Unit, Colombo, Sri Lanka; ${ }^{2}$ Ministry of Health, Colombo, Sri Lanka

\subsection{6/oemed-2013-101717.36}

Objectives To describe the provision of occupational health services to workers in small scale industries in a district of Sri Lanka Methods A cross-sectional study was conducted among workers in selected small scale industries in Gampaha district in Sri Lanka. A small scale industry was defined as a work setting with less than 20 workers. The study population consisted of workers in four selected small scale industry categories namely food and beverages, apparel, non metallic mineral products and fabricated metal products. Full time, permanent, workers between the ages of 18-65 years with at least 6 months were selected. Pregnant and temporary workers were excluded. The Census of Industry 2003/2004 was used as the sampling frame. The required sample size was 640 and sampling was done using cluster sampling using probability proportionate to size of workers with a cluster size of eight and 80 clusters. Data was collected using an interviewer administered questionnaire. 